\title{
Differentiation of South African coastal rock pool Ochthebius is associated with major ocean currents (Coleoptera: Hydraenidae)
}

\section{Bilton, David}

http://hdl.handle.net/10026.1/17311

10.37520/aemnp.2021.015

Acta Entomologica Musei Nationalis Pragae

National Museum, Czech Republic

All content in PEARL is protected by copyright law. Author manuscripts are made available in accordance with publisher policies. Please cite only the published version using the details provided on the item record or document. In the absence of an open licence (e.g. Creative Commons), permissions for further reuse of content should be sought from the publisher or author. 


\title{
Differentiation of South African coastal rock pool Ochthebius is associated with major ocean currents (Coleoptera: Hydraenidae)
}

\author{
David T. BILTON ${ }^{1,2)}$ \\ 1) Marine Biology and Ecology Research Centre, School of Biological and Marine Sciences, University of Plymouth, Drake Circus, Plymouth PL4 \\ 8AA, UK; e-mail: d.bilton@plymouth.ac.uk \\ ${ }^{2)}$ Department of Zoology, University of Johannesburg, PO Box 524, Auckland Park, Johannesburg 2006, South Africa
}

Accepted:

$26^{\text {th }}$ June 2021

Published online: $5^{\text {th }}$ July 2021

\begin{abstract}
A number of non-marine coastal invertebrate species have been found to constitute (semi-) cryptic species complexes in recent years. Here it is revealed that rather than a single widespread species, distributed from the Namibian border to the Cape south coast, South African coastal rock pool Ochthebius Leach, 1815 previously referred to Ochthebius capicola (Péringuey, 1892) comprise two distinct taxa. Ochthebius capicola (s. str.) is apparently restricted to the Benguela Ecoregion on the west coast, being replaced by Ochthebius mlamboi sp. nov., in south and east coast localities influenced by the Agulhas Current, including areas of the Eastern Cape province well outside the previous known range of these beetles. The distribution and ecology of the two species is discussed, with reference to biogeographic breaks in southern African coastal taxa, and the emerging view that many 'widespread' coastal rock pool Ochthebius may actually be (semi-) cryptic species complexes.
\end{abstract}

Key words. Aquatic Coleoptera, Hydraenidae, Ochthebius, supralittoral, new species, South Africa

Zoobank: http://zoobank.org/urn:lsid:zoobank.org:pub:C69150CF-8689-4A6B-A672-4542B46BB650

(C) 2021 The Authors. This work is licensed under the Creative Commons Attribution-NonCommercial-NoDerivs 3.0 Licence.

\section{Introduction}

A number of supposedly widespread non-marine coastal invertebrate species have been revealed to constitute (semi-) cryptic species complexes in recent years (e.g. HurTado et al. 2014; SANTAMARIA et al. 2016, 2017), including in southern Africa (BALDANZI et al. 2016, GREENAN et al. 2017, MBongwa et al. 2019). Most studies to date have concerned non-volant taxa such as terrestrial isopods, which lack an aquatic larval stage and cannot survive prolonged immersion in saltwater.

Ochthebius Leach, 1815 beetles are amongst the dominant macroinvertebrates present in coastal supralittoral rock pools in many parts of the world, particularly in the northern hemisphere (SABATELLI et al. 2016). Detailed genetic and morphological studies have revealed previously overlooked, relatively cryptic taxa in rock pool dwelling members of the quadricollis and vandykei groups of the subgenus Ochthebius (e.g. URBANELLI 2002; URBANELLI et al. 1996, 2008; JÄCH \& DeLgado 2014) and the subgenus Cobalius Rey, 1886 (e.g. RIBERA \& FosTer 2018, VILLASTRIGO et al. 2020). The other lineage of Ochthebius known to have shifted to a coastal rock pool existence is currently comprised of $O$. capicola (Péringuey, 1892) and O. rubripes Boheman, 1861. Both species were placed in the subgenus Notochthebius d'Orchymont, 1933 by Perkins \& Balfour-Browne (1994), who noted that "Further study will probably show that 'Notochthebius' is actually a subunit of Ochthebius (s.s.)". PERKINs (1997) chose to synonymise Notochthebius with Ochthebius (s. s.), a decision supported by the genetic work of VILLASTRIGO et al. (2019) who showed that $O$. capicola was related to southern African species of inland saline waters, such as O. pedalis Balfour-Browne, 1954 and O. spinasus Perkins \& Balfour-Browne, 1994. Of the two known rock pool species in southern Africa, O. rubripes has to date only been reported from Namibia and the Richtersveld coast 
in the far north of South Africa. Ochthebius capicola cooccurs with $O$. rubripes in the Richtersveld, extending from there south and east along the South African coast to Port Elizabeth. Here, on the basis of recently collected material, I show that $O$. capicola as previously understood actually includes two distinct species, apparently associated with the Benguela and Agulhas current systems respectively.

\section{Materials and methods}

Beetles were collected from supralittoral rock pools by hand. Specimens were studied using Leica MZ8 and 205C stereomicroscopes, with LED gooseneck lights diffused using a tracing paper collar and tubes derived from opaque white plastic film canisters. Habitus photographs were taken with a Canon EOS 5D mark IV camera fitted to a Leica $205 \mathrm{C}$ stereomicroscope, with a $1 \times$ objective lens. Specimens were illuminated using gooseneck lights, diffused with a film canister tube.

Genitalia were mounted on glass slides in Kisser's glycerol gelatine (see RIEDEL 2005) and imaged using an Olympus CX31 microscope and a Canon 500D camera. All image stacks were produced by hand, and combined using Zerene Stacker software (www.zerenesystems.com).

Exact label data are cited for specimens. / indicates new line in label text; // indicates separate labels.

Abbreviations:

AMGS Albany Museum, Grahamstown, South Africa;

CDTB Collection D.T. Bilton, Plymouth, UK;

MCZH Museum of Comparative Zoology, Harvard, USA;

NHMUK Natural History Museum, London, UK;

NHMW Naturhistorisches Museum Wien, Vienna, Austria;

NMPC Národní muzeum, Prague, Czech Republic;

SAMC Iziko South African Museum, Cape Town, South Africa;

SANC South African National Collection of Insects, Pretoria, South Africa;

TMSA Ditsong Museum (former Transvaal Museum), Pretoria, South Africa;

BL Body length (front of labrum to elytral apices);

EL Elytral length (outer angle of shoulder to apex);

EW Elytral width at widest point.

\section{Taxonomy}

\section{Ochthebius capicola (Péringuey, 1892)} (Figs 1A,C, 2A,C)

Hydraena capicola Péringuey, 1892: 106.

Ochthebius capicola: D'ORCHYMONT (1933): 411 (new combination); Perkins \& Balfour Browne (1994): 151 (partim) (lectotype designation).

Material examined. SOUTH AFRICA: Western CAPE Prov: $6 \lesssim \partial$ 7 우 (CDTB) '19/ix/2008 South Africa WC/ Boulders Beach, Simons/ Town, rock pools D T Bilton leg.'; 5 \ิ 5 q (CDTB) ‘22/ix/2014 South Africa WC/ Yzerfontein beach/ rock pools D T Bilton leg.’; 9 ๙ 9 우 (AMGS, CDTB, NHMW, NMPC, SAMC) '23/ix/2019 South Africa WC/ Yzerfontein beach/ rock pools D T Bilton leg.'; 62 spec. (NHMUK) 'S. AFRICA:/ Cape Town,/ Sea Point,/ 27.iii.1954.// in rock-pools of/ splashzone// J. Balfour-Browne/ Brit. Mus. 1954-797// Ochthebius/ capicola/ (Peringuey)/ Det. P. D. Perkins'; 1 'South Africa, Western Cape/ Cape Town, Sea Point,/ A. Skale, 05.06.2001’'

Redescription. Size: $\widehat{\jmath}$ BL 1.95-2.35 mm; EL 1.30-1.35 $\mathrm{mm}$; EW 0.85-1.00 mm. ㅇ BL 2.05-2.95 mm; EL $1.30-1.50 \mathrm{~mm}$; EW 0.95-1.05 mm.
Colour: Dorsum (Fig. 1A) brown to blackish, with greenish to coppery aeneous reflections, these sometimes covering most of upper surface with exception of lateral margins of pronotum, exposed mandible margins and labral apex, these areas being paler. Legs testaceous to brown; maxillary palpi and basal antennomeres yellow to pale testaceous, club segments darker. Venter piceous; palpifer and pronotal hypomeron paler.

Head: Labrum slightly transverse, broadly rounded laterally with straight to weakly emarginate, slightly thickened and raised apical margin; sides and apex minutely serrate. Surface of labrum dull, microreticulate, meshes isodiametric to slightly transverse; with sparse-moderate, medium punctures, bearing white, decumbent setae. Frontoclypeal suture distinct, arcuate, becoming weaker laterally. Clypeus, frons and vertex somewhat dull with aeneous reflections; with somewhat rugulose microreticulation of mostly isodiametric meshes and sparse-moderate, medium punctures bearing long, white, decumbent setae; reticulation especially strong on frons and vertex, becoming transverse on posterior vertex and occiput, here absent centrally. Interocular foveae shallow, relatively small, but abrupt. Ocelli obsolete, shining, reduced to patches approx. 2-4 reticulation meshes in size and not distinctly raised. Compound eyes moderately sized, occupying approx. 0.4 side of head, 8-10 ommatidia in longest series.

Pronotum: Widest just behind anterior angles, then gradually attenuate to posterior angles (Fig. 2A). Anterior margin broadly but very shallowly arcuate over median 0.6 ; posterior margin rounded; lateral margins straight behind widest point, anteriorly arcuate to anterior angles. Anterior and posterior angles obtusely rounded, the latter more so. Anterior and posterior margins with broad hyaline border; lateral margins with narrower hyaline border from just behind widest point to posterior angles, becoming broader posteriorly and continuous with hyaline edge of posterior margin. Surface weakly shining, with aeneous reflection, especially on disc; disc close to anterior and posterior margins strongly and subrugulosely microreticulate, where distinct isodiametric meshes are visible; elsewhere microreticulation highly rugulose, surface appearing micropunctate, with confluent, typically aeneous, raised areas between non-shiny depressions; entire surface with sparse, fine punctures bearing long, white, recumbent to decumbent setae. Irregular row of larger punctures, bearing long, white suberect setae along anterior margin each side of median emargination. Disc with very shallow, almost obsolete transverse impressions in front of and behind middle. Lateral depressions shallow, broad, expanded anterolaterally and nearly reaching anterior angles; shallowly, subrugosely punctate; microreticulation meshes not visible here. Lateral depressions and adjacent lateral areas of pronotum corrugated, with short transverse and somewhat longer longitudinal, shiny ridges between punctures.

Elytra: Elongate oval, broadest anteriorly; almost subparallel over anteromedian 0.3 , then weakly attenuated to separately rounded hind angles. Anterior angles broadly rounded; shoulders distinct. Lateral margins very narrowly explanate. Elytral punctures (Fig. 2C) random, 
A
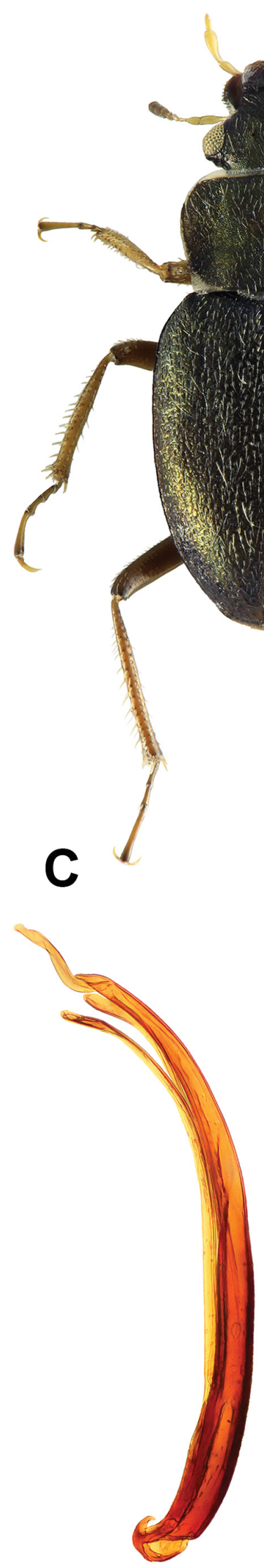

B

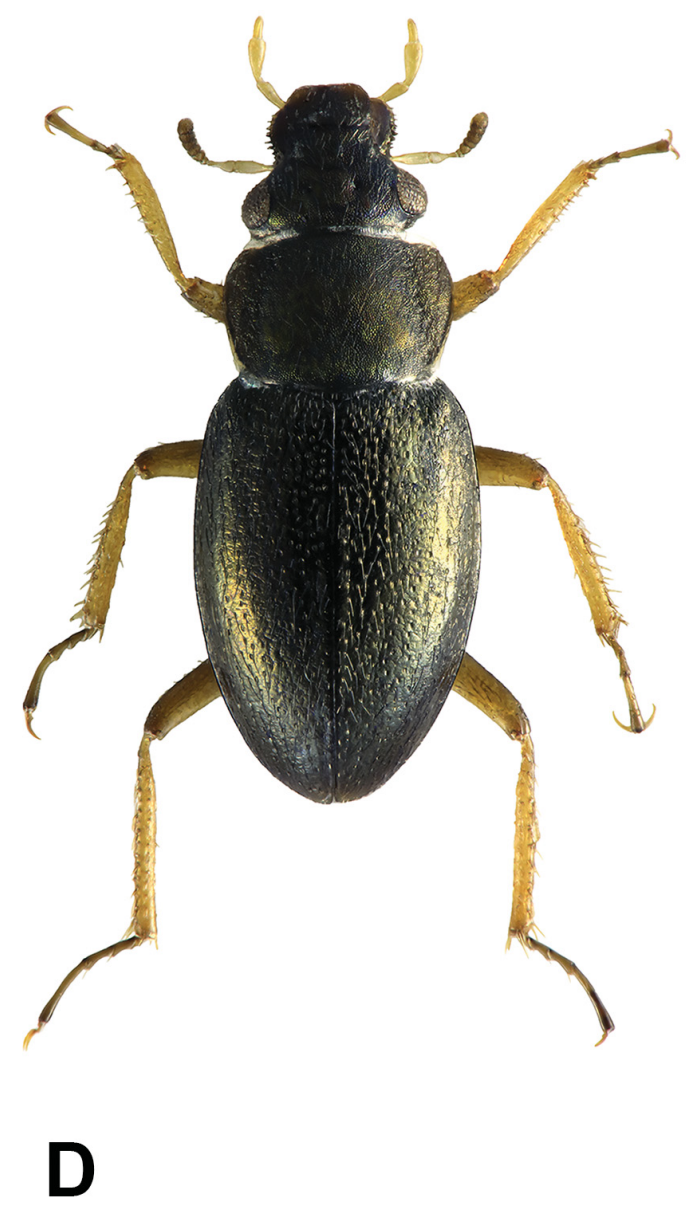

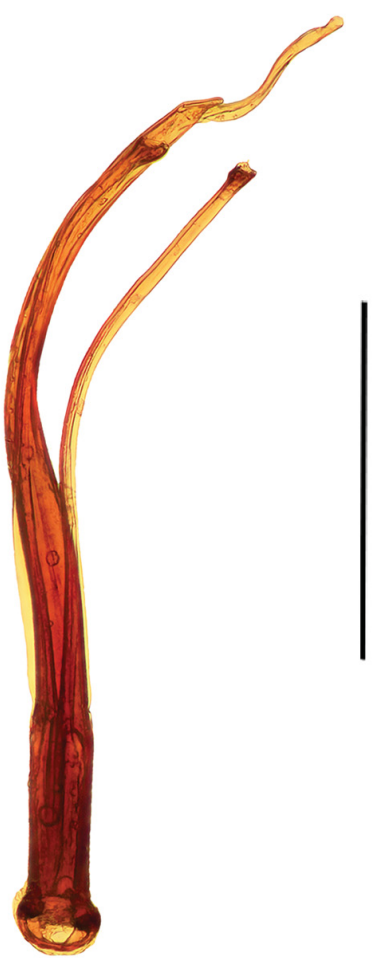
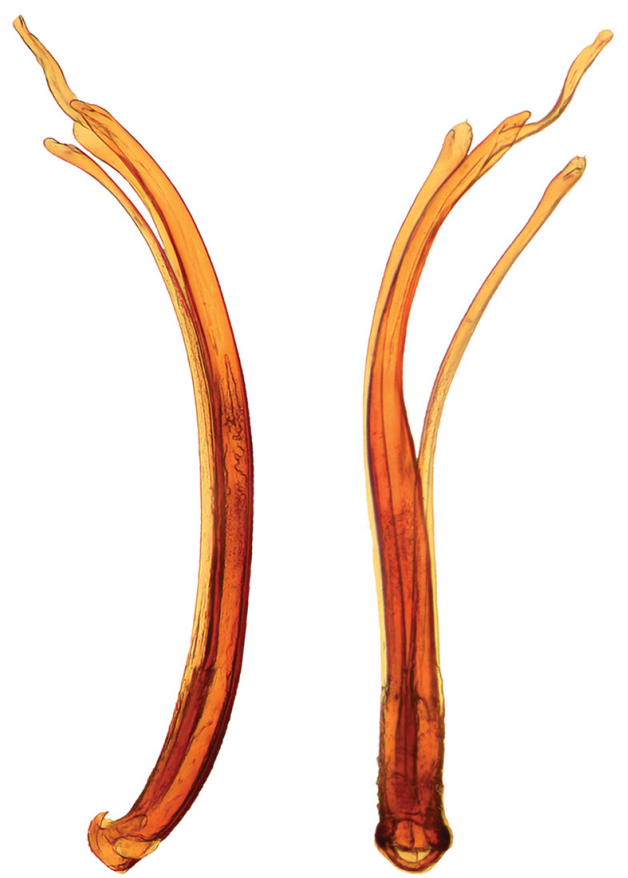

Fig. 1. Ochthebius species. A - O. capicola (Péringuey, 1892) (Yzerfontein, Western Cape Province), male habitus; B - O. mlamboi sp. nov., holotype habitus; C - O. capicola (Péringuey, 1892) (Yzerfontein, Western Cape Province), aedeagus, lateral and ventral views; D - O. mlamboi sp. nov., holotype aedeagus, lateral and ventral views. Scale bar A-B $=1 \mathrm{~mm} ; \mathrm{C}-\mathrm{D}=0.25 \mathrm{~mm}$. 

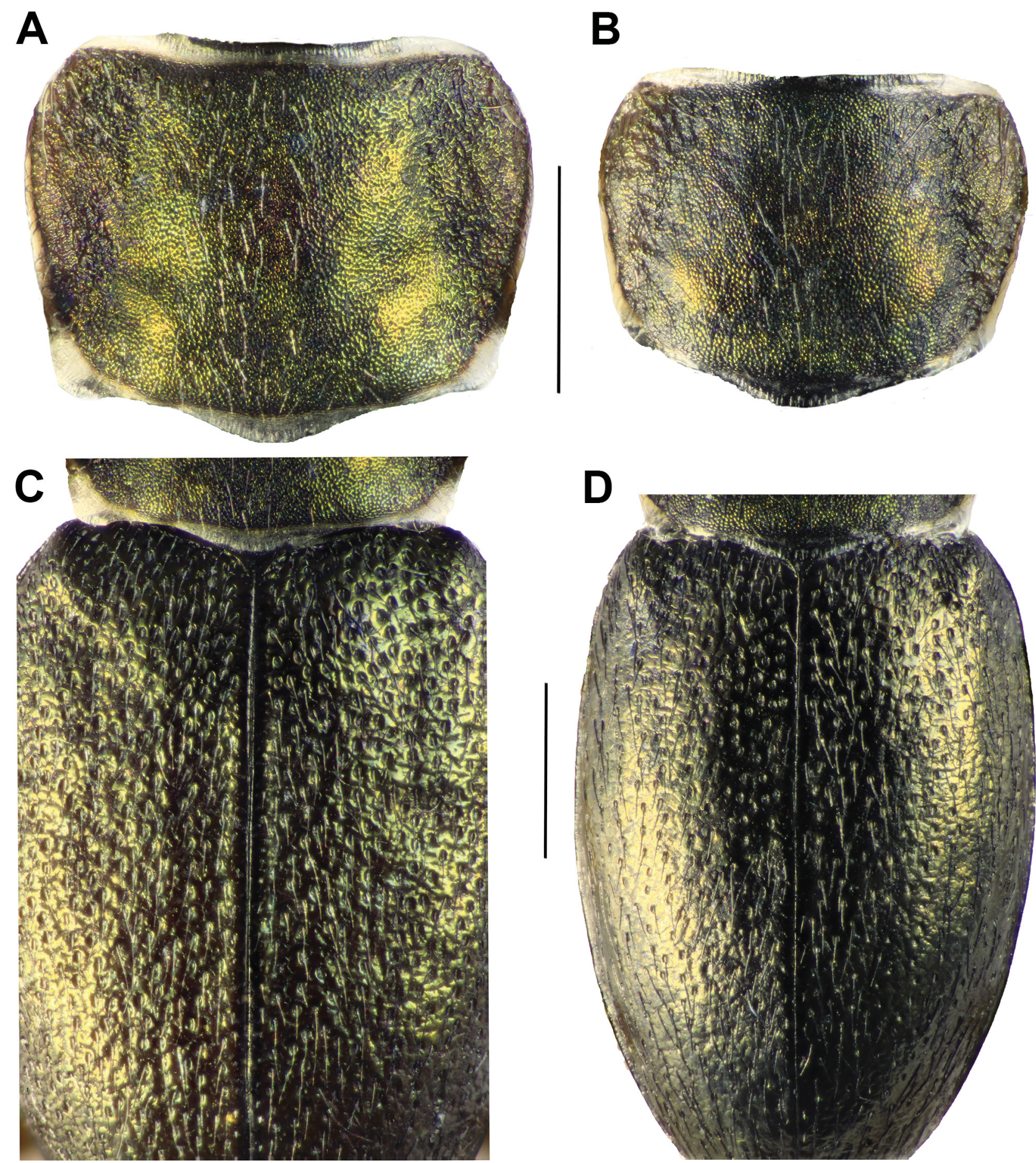

Fig. 2. Ochthebius species, showing dorsal sculpture A \& C - O. capicola (Péringuey, 1892) (Yzerfontein, Western Cape Province); B \& D - O. mlamboi sp. nov. A \& B - pronota; C \& D - elytra. Scale bars $=0.5 \mathrm{~mm}$.

no trace of longitudinal series. Punctures close, coarse and deep anteriorly, almost confluent on disc behind shoulder; shallower posteriorly; all bearing long, white, recumbent setae. Interstices subrugulose, with open microreticulation of large, deeply impressed meshes, often reduced to transverse channels; more shining than head and pronotum, with aeneous reflection.

Legs: Elongate, slender, metatibial length slightly less than pronotal width. Protarsomeres 1-2 slightly widened and with pad of suction setae.
Venter: Mentum, submentum, and genae shining, microreticulation restricted to transverse ridges on outer areas of genae; mentum and submentum with sparse, fine punctures, bearing fine, white decumbent setae. Gula with dense, fine to medium punctures bearing short recumbent setae; surface shining between punctures, but overall appearance at low magnification dull. Antennal pockets well developed. Prosternum rugosely microreticulate and punctate, punctures bearing long, erect to recumbent setae which form part of the hydrofuge vestiture; mesoventrite 
same, but reticulation and punctures less impressed and dense, and vestiture sparser. Pronotal hypomeron broad, wet hypomeron shining, glabrous; hypomeral antennal pocket well developed. Elytral epipleurs broad anteriorly, narrowing gradually to ca. 0.2 from apex; surface shining, with sparse, scattered setae and narrow strip of hydrofuge vestiture interiorly over anterior 0.3 ; row of short, curved setae running along edge of narrow posterior 0.2 . Metaventrite with isodiametric to transverse microreticulation, stronger at sides, somewhat obsolete in centre; with dense, fine punctures bearing shaggy hydrofuge vestiture; vestiture denser laterally, sparse and often rubbed off in central area. Abdominal ventrites 1-5 completely and 6 laterally with slightly transverse, rugulose microreticulation and densely hydrofuge pubescent; ventrite 6 medially sparsely pubescent over apical 0.6 , shining; apical 0.5 of glabrous area entirely devoid of microreticulation, punctures and vestiture, strongly shining. Apical tergum sharply rounded, with tuft of long flagelliform setae on each side and few spiniform setae.

Aedeagus: Elongate (Fig. 1C), main piece curved in lateral view, particularly towards the apex; strongly curving to the right in ventral view. Apex of main piece relatively acute, rapidly attenuated, particularly in ventral view. Distal lobe narrow, elongate, sinuous. Parameres inserted close to base; elongate, narrow, curved as main piece in lateral view; apices slightly expanded, somewhat truncate in ventral view.

Female: Differs from the male in the following characters: labral margin not so strongly raised; lateral setae of mandibles smaller; explanate elytral margin broader; elytral apices conjointly rounded, but sutural margin emarginate just before apices (making apices appear slightly pointed); median 0.3 of ventrite 1 reduced to narrow, membranous strip, sternum on each side appearing somewhat triangular; apical tergum more angulately rounded, long setae curling away from midline and spiniform setae slightly more numerous; protarsomeres narrower, without suction setae; many specimens examined with elytra somewhat paler than in males.

Variation. In addition to small variations in size, specimens vary in colouration, some being paler than the individual illustrated, particularly on the elytra. There is also some variation in the density of the elytral punctation, some specimens from False Bay (Boulders Beach) having slightly sparser punctures on the disc than others and those from the West Coast. The aedeagus shows little variation in size and overall appearance, but some individuals examined have shorter distal lobes than illustrated, this variation being observed amongst specimens collected from the same pool. Differential diagnosis. Both this species and $O$. mlambo sp. nov. are distinguished from $O$. rubripes by their random elytral punctation, equally microreticulate head and pronotum, the proportionally smaller elytra, smaller body sizes, and the aedeagi (see PERKIns \& BALFour-BrownE 1994). For separation of O. capicola from O. mlamboi sp. nov., see under the latter species below.

Comments. The type material (SAMC) consists of two damaged female specimens from Cape Town, which were designated as Lectotype and Paralectotype respectively by PERKIns \& BALFOUR-Browne (1994). These were not available for re-examination, but topotypic specimens all belong to the taxon as interpreted here. Details of Richtersveld specimens (3 spec.) were communicated by P. D. Perkins, who confirmed that they matched O. capicola $\mathrm{s}$. str. on both external sculpture and aedeagal characters.

Distribution and ecology. As newly defined, this species is largely restricted to the west coast of South Africa, from the Cape Peninsula in the south to the Namibian border (Richtersveld) in the north (Fig. 3). It also occurs on the western shore of False Bay at Boulders Beach. The precise respective geographical limits of $O$. capicola and $O$. mlamboi sp. nov. in the Western Cape remain unclear, but like a number of other coastal taxa, this seems likely to be situated in False Bay (see Discussion). In all localities, the species is characteristic of supralittoral rock pools, typically occurring in small, typically eutrophic and highly anoxic pools in the splash zone on rocky coastlines. Adults and presumed larvae are, like most rock pool Ochthebius, often observed together grazing biofilms. Clusters of laboulbenial fungi of the genus Hydrophilomyces Thaxter, 1908 have been observed on the posterior central metaventrite of specimens from Yzerfontein; a different, unidentified laboulbenial genus being present on the prosternum of some of the same beetles.

\section{Ochthebius mlamboi sp. nov.} (Figs 1B, D, 2B, D)

Type material. HоLотYPE: $\curvearrowright$ ' $9 / \mathrm{ix} / 2019$ South Africa EC/ Mkambati Nature Reserve/ supralittoral rock pools below Point Cottage/ 31 19 '09.08'S $29^{\circ} 58$ 20.46”'E, 3 m/ AMG Loc. 218 D T Bilton leg.' (AMGS). With red holotype label. PARATYPES: 13 \% 10 + (AMGS, CDTB, NHMW, NMPC, SAMC) same data as holotype; $3 \precsim 2$ oq (CDTB) '23/ix/2008 South Africa EC/ Tsitsikamma Storms River/ Mouth rockpools/ D T Bilton leg.; $1 \delta 1+$ (CDTB) 21/ix/2009 South Africa EC/ Tsitsikamma NP waterfall pools ca./ $3.5 \mathrm{~km}$ along Otter Trail W of Storms/ River Mouth

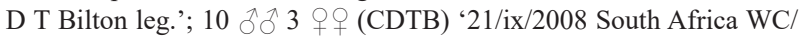
Plettenberg Bay rockpools/ D T Bilton leg.'; $1 \precsim$ (CDTB) ix/2017 South Africa EC/ Sea View ca. $6 \mathrm{~km}$ W of Port Elizabeth/rockpools D T Bilton leg.'; 1 \ 2 ㅇ (NHMW) 'RSA: Eastern Cape, 6.3.1997/ Tsitsikamma Mts./ 40km E Plettenberg Bay/ $34^{\circ} 05^{\prime} \mathrm{S} 23^{\circ} 21^{\prime} \mathrm{E} / \mathrm{leg}$. Hess \& Heckes (19)'; 4 ๆ (NHMW) 'RSA, Eastern Cape Tsitsi-/ kamma Mts: $40 \mathrm{~km} \mathrm{E}$ Pletten-/ berg Bay, 2km E Storms Ri-/ ver Mouth, bis 30m NN./ 6.3.1997 Hess/Heckes leg.'; 108 spec. (MCZH, NHMUK) 'S. AFRICA:/ Knysna Heads./ 16.iii.1954.// in rock-pools of/ splash-zone// J. Balfour-Browne/ Brit. Mus. 1954-797// Ochthebius/ capicola/ (Peringuey)/ Det. P. D. Perkins'; 33 spec. (NHMUK) 'S. AFRICA:/ Knysna Heads./ 16.iii.1954.// in rock-pools of/ splash-zone// J. Balfour-Browne/ Brit. Mus. 1954-797’; 22 spec. (MCZH, NHMUK) 'S. AFRICA:/ Skoermakerskop,/ nr. Port Elizabeth./ vi. 1959/ B. R. Stuckenberg.// Ochthebius/ capicola/ (Peringuey)/ Det. P. D. Perkins'. All with red paratype labels.

Description. Size: Holotype: BL $1.95 \mathrm{~mm}$; EL $1.15 \mathrm{~mm}$; EW $0.80 \mathrm{~mm}$. Paratypes: के $\frac{\mathrm{B}}{\mathrm{BL}} 1.90-2.00 \mathrm{~mm}$; EL $1.10-1.15 \mathrm{~mm}$; EW $0.80-0.85 \mathrm{~mm}$. ㅇ $\mathrm{BL} 1.80-2.05 \mathrm{~mm}$; EL 1.05-1.20 mm; EW 0.75-0.85 mm.

Colour: Dorsum (Fig. 1B) brown to blackish, with greenish to coppery aeneous reflections, these sometimes covering most of upper surface with exception of lateral margins of pronotum, lateral and apical areas of elytra, exposed mandible margins and labral apex, these areas being paler. Legs testaceous to brown; maxillary palpi 
and basal antennomeres yellow to pale testaceous, club segments darker. Venter piceous; palpifer and pronotal hypomeron paler.

Head: Labrum slightly transverse, broadly rounded laterally with straight, slightly thickened and raised apical margin, particularly in centre; sides and apex minutely serrate. Surface of labrum dull, microreticulate, meshes isodiametric to slightly transverse; with sparse-moderate, medium punctures, bearing white, decumbent setae. Frontoclypeal suture distinct, arcuate, becoming weaker laterally. Clypeus, frons and vertex somewhat dull with aeneous reflections; with somewhat rugulose microreticulation of mostly isodiametric meshes and sparse-moderate, medium punctures bearing long, white, decumbent setae; reticulation especially strong on frons and vertex, becoming transverse on posterior vertex and occiput, here absent centrally. Interocular foveae shallow, relatively small, but abrupt. Ocelli obsolete, shining, reduced to patches approx. 2-4 reticulation meshes in size and not distinctly raised. Compound eyes moderately sized, occupying approx. 0.4 side of head, 8-10 ommatidia in longest series.

Pronotum: Widest just behind anterior angles, then gradually attenuate to posterior angles (Fig. 2B). Anterior margin broadly but very shallowly arcuate over median 0.7 ; posterior margin rounded; lateral margins straight behind widest point, anteriorly arcuate to anterior angles. Anterior and posterior angles obtusely rounded, the latter more so. Anterior and posterior margins with distinct hyaline border; lateral margins with narrower hyaline border from just behind widest point to posterior angles, becoming broader posteriorly and continuous with hyaline edge of posterior margin. Surface weakly shining, with aeneous reflection, especially on disc; strongly microreticulate, with isodiametric to slightly transverse meshes; meshes distinct in lateral areas, outside lateral depressions; entire surface with sparse, fine punctures bearing long, white, recumbent to decumbent setae. Irregular row of larger punctures, bearing long, white suberect setae along anterior margin each side of median emargination. Disc with very shallow, almost obsolete transverse impressions in front of and behind middle. Lateral depressions shallow, broad, expanded anterolaterally and nearly reaching anterior angles; shallowly, subrugosely punctate.

Elytra: Elongate oval, broadest anteriorly; weakly curved to almost subparallel over anteromedian 0.3, then weakly attenuated to separately rounded hind angles. Anterior angles broadly rounded; shoulders distinct. Lateral margins very narrowly explanate. Elytral punctures random, no trace of longitudinal series. Punctures (Fig. 2D) moderately dense, moderate in size and relatively shallow, particularly posteriorly; all bearing long, white, recumbent setae. Interstices flat, with microreticulation mostly restricted to shallow transverse channels; more shining than head and pronotum, with aeneous reflection.

Legs: Relatively elongate, metatibial length slightly less than pronotal width. Protarsomeres 1-2 slightly widened and with pad of suction setae.

Venter: Mentum, submentum, and genae shining, microreticulation restricted to transverse ridges on outer areas of genae; mentum and submentum with sparse, fine punctures, bearing fine, white decumbent setae. Gula with dense, fine to medium punctures bearing short recumbent setae; surface shining between punctures, but overall appearance at low magnification dull. Antennal pockets well developed. Prosternum rugosely microreticulate and punctate, punctures bearing long, erect to recumbent setae which form part of the hydrofuge vestiture; mesoventrite same, but reticulation and punctures less impressed and dense, and vestiture sparser. Pronotal hypomeron broad, wet hypomeron shining, glabrous; hypomeral antennal pocket well developed. Elytral epipleurs broad anteriorly, narrowing gradually to ca. 0.2 from apex; surface shining, with sparse, scattered setae and narrow strip of hydrofuge vestiture interiorly over anterior 0.3 ; row of short, curved setae running along edge of narrow posterior 0.2. Metaventrite with isodiametric to transverse microreticulation, stronger at sides, somewhat obsolete in centre; with dense, fine punctures bearing shaggy hydrofuge vestiture; vestiture often rubbed off in central area. Abdominal ventrites 1-5 completely and 6 laterally with slightly transverse, rugulose microreticulation and densely hydrofuge pubescent; ventrite 6 medially sparsely pubescent, shining; apical 0.8 entirely without vestiture, apical 0.5 of glabrous area devoid of microreticulation and punctures, strongly shining. Apical tergum sharply rounded, with tuft of long flagelliform setae on each side and few spiniform setae.

Aedeagus: Elongate (Fig. 1D), main piece curved in lateral view; strongly curving to the right in ventral view. Apex of main piece bluntly pointed in lateral and ventral views. Distal lobe narrow, elongate, sinuous. Parameres inserted close to base; elongate, narrow, curved as main piece in lateral view; apices slightly expanded, rounded in ventral view.

Female: Differs from the male in the following characters: labral margin not so strongly raised; lateral setae of mandibles smaller; explanate elytral margin broader; median 0.3 of ventrite 1 reduced to narrow, membranous strip, sternum on each side appearing somewhat triangular; apical tergum more angulately rounded, long setae curling away from midline and spiniform setae slightly more numerous; protarsomeres narrower, without suction setae; many with elytra somewhat paler than in males, particularly laterally and apically.

Variation. In addition to small variations in size, specimens vary in colouration, some being paler than the individual illustrated, particularly on the elytra. There is also some variation in the strength of elytral reticulation, specimens examined from the western part of the known range (Port Elizabeth, Tsitsikamma and Plettenberg Bay) having slightly stronger reticulation than those from the type locality. The aedeagus shows little variation in size and overall appearance, but some individuals examined have shorter distal lobes than illustrated, this variation being observed amongst specimens collected from the same locality.

Differential diagnosis. Despite resembling O. capicola, the new species can be distinguished from it on both external and genitalic characters. Firstly, O. mlamboi sp. nov. is smaller than $O$. capicola (TL $1.80-2.05 \mathrm{~mm}$ vs. $1.95-$ 
$2.95 \mathrm{~mm}$, respectively - see Figs 1 A \& B); a difference which, despite some overlap, is usually apparent even with the naked eye. Ochthebius mlamboi sp. nov. has pronotal reticulation (Fig. 2B) formed of distinct, typically isodiametric meshes throughout the disc, very different from the finely rugulose reticulation seen in $O$. capicola (Fig. 2A). The pronotum of $O$. capicola also differs in the corrugated surface of the areas outside the lateral depressions, in which reticulation is not visible; meshes here being clear in $O$. mlamboi sp. nov. The elytral punctation of the two species also differs significantly (Figs 2C \& D); whilst both have a random pattern of punctation, the punctures of $O$. capicola are denser and deeper than those of $O$. mlamboi sp. nov., particularly on the disc. The interstices of $O$. mlamboi $\mathrm{sp}$. nov. have sparser and less impressed microreticulation channels than in $O$. capicola. There are also slight differences in the sculpture of abdominal ventrite 6 , which has a relatively larger glabrous patch in $O$. mlamboi sp. nov. Lastly, the aedeagi (Figs 1C \& D) of the two species differ; that of $O$. capicola is larger (main piece length $0.58-0.60$ vs. $0.52-0.54 \mathrm{~mm}$ ), has a main piece which curves more abruptly apically, and has a more finely pointed apex. A specimen from Mkambati exhibited ca. 5\% divergence in mitochondrial COI sequence from individuals of $O$. capicola from Yzerfontein and Simons Town (I. Ribera, pers. comm.). For separation of $O$. mlamboi sp. nov. from $O$. rubripes, see under $O$. capicola.

Etymology. Named for my friend and colleague, Dr Musa C. Mlambo, Albany Museum, Grahamstown, South Africa, who assisted with the collection of part of the type series; in recognition of many enjoyable joint field trips.

Distribution and ecology. The new species is apparently widely distributed on the southern and southeast coasts of South Africa, being known to date from Mkambati in the East to Plettenberg Bay in the west (Fig. 3). The species is apparently replaced by $O$. capicola from the west coast of False Bay northwestwards, but both the western and northeastern limits of its distribution will need to be confirmed by future fieldwork. As with a number of other coastal taxa, the boundary between the two species may be situated in False Bay (see Discussion). All specimens have been collected from supralittoral rock pools, as with O. capicola.

\section{Discussion}

The rock pool Ochthebius revised here clearly comprise two distinct taxa, one of which is distributed much further northeast than was previously reported for O. capicola s. lat. VON DER HEYDEN (2009) summarised known genetic discontinuities in marine littoral taxa along southern African coasts, these often being associated with oceanographic features, including currents; the Benguela and Agulhas in particular. The Benguela Current supplies cold water to the west coast of South Africa and Namibia and is characterised by strong upwelling, leading to high primary productivity. In contrast, the Agulhas Current brings relatively warm water to the eastern and southern coasts of South Africa, its influence extending to False Bay and the eastern side of the Cape Peninsula in the west (BRANCH \& BRANCH 2018). The boundary between the Benguela and Agulhas currents has been shown to be associated with genetic breaks within species, or turnover between species and communities (e.g. BRANCH et al. 2017). The exact boundary between 'Benguela' and 'Agulhas' taxa or lineages is not concordant across different groups, however, this sometimes differing between closely related species (e.g. MBONGWA 2018). In many taxa, such as supralittoral Tylos isopods (KensLEY 1972) turnover occurs at Cape Point, but in other lineages this happens further east, False Bay being a frequent location of the contact zones between taxa (VON DER HEYDEN 2009). Further fieldwork will be required to locate the exact position of the transition between $O$. capicola and $O$. mlamboi sp. nov., and whether they co-occur in any localities. On the basis of current data,

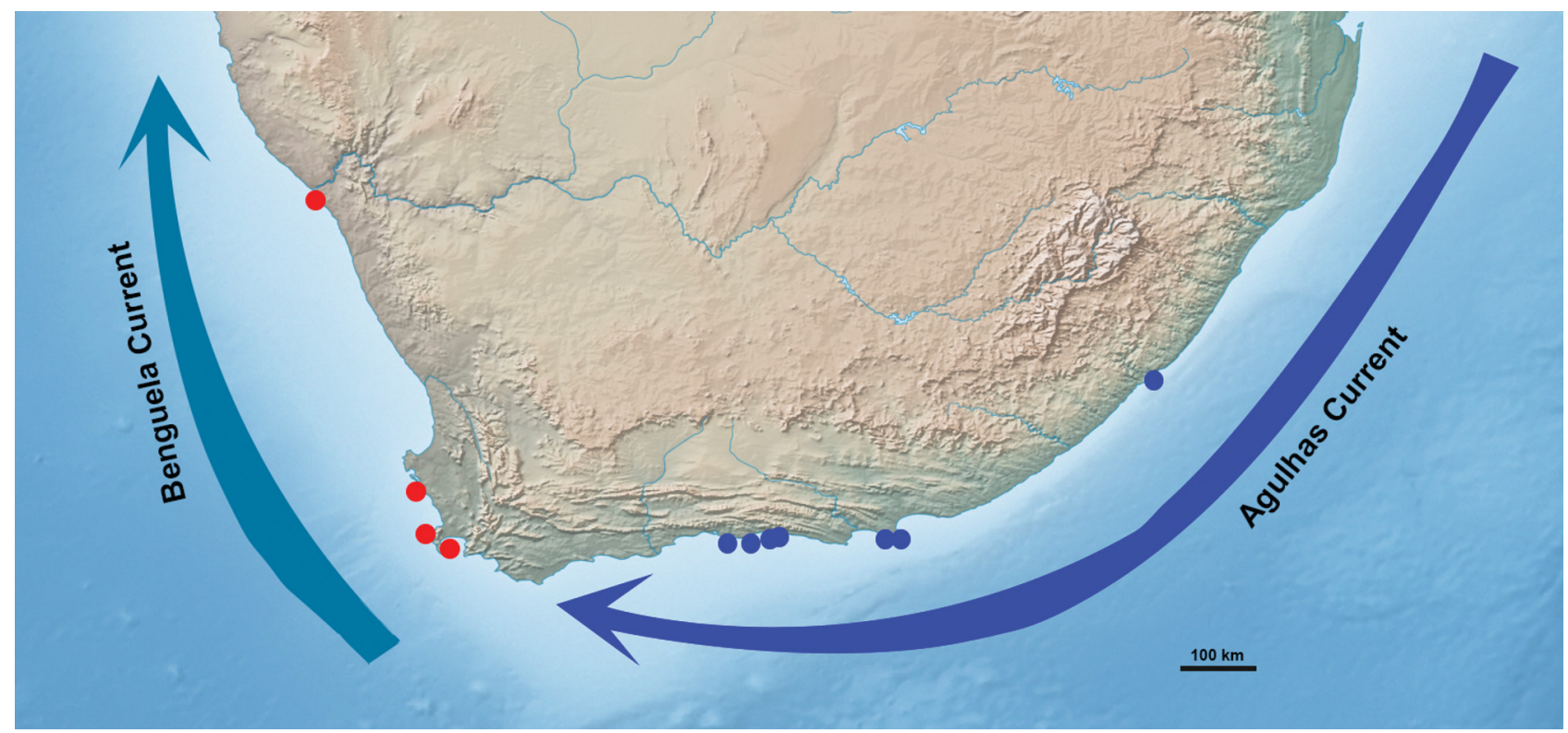

Fig. 3. Distribution of material examined, with approximate positions of major ocean currents. Red symbol - O. capicola (Péringuey, 1892); blue symbol - O. mlamboi sp. nov. 
however, it is clear that this is located somewhere to the east of Cape Point. The two species now recognised within O. capicola $\mathrm{s}$. lat. are relatively distinct morphologically, on both external and genitalic characters, markedly more so than cryptic rock pool Ochthebius recently reported in the Mediterranean Basin and Macaronesia. mtDNA COI sequence divergence suggests these taxa separated just over 2 MYA, in the early Pleistocene, a time when changes to sea level and ocean currents may have driven population isolation. Genetic studies of South African rock pool Ochthebius will be required to determine whether these taxa contain further cryptic lineages. In the light of the discovery of $O$. mlamboi sp. nov. at Mkambati on the Wild Coast, far to the northeast of all previous records of rock pool Ochthebius, it seems likely that exploration of these habitats elsewhere in Africa will reveal further, undescribed species of the genus.

\section{Acknowledgements}

I am grateful to Musa Mlambo, Ayanda Mlambo, Zizile Mlungu and Alvaro Vetina, for their company on our visit to Mkambati and assistance in the field, as well as to Nick Helme for recommending this location. I also thank Max Barclay (BMNH) for loans of $O$. capicola specimens. Michael Samways (Stellenbosch University), Lee-Anne Benjamin, Danelle Kleinans, Deon Hignet (Cape Nature), Ruth-Mary Fisher and Deborah Winterton (Table Mountain National Park), Nomatile Nombewu (Eastern Cape Parks and Tourism Agency) have all kindly assisted with sampling permits over the years. The late Ignacio Ribera freely shared results of preliminary investigations of mtDNA variation in this group and Sergi Santamaria (Barcelona) kindly identified the Hydrophilomyces fungus. Werner Strumpher (TMSA) kindly loaned material of Ochthebius rubripes for comparison and Phil Perkins provided details of Richtersveld specimens of Ochthebius capicola.

\section{References}

BALDANZI S., GOUWS G., BARKER N. P. \& FRATINI S. 2016 : Molecular evidence of distinct evolutionary units in the sandhopper Talorchestia capensis (Amphipoda, Talitridae) along South African coasts. Hydrobiologia 77: 35-46.

BALFOUR-BROWNE J. 1954: A preliminary contribution to the knowledge of the South African Palpicornia (Coleoptera). (Professor J. Omer-Cooper's investigation of the inland waters of Africa.) Journal of the Entomolological Society of South Africa 17: 96-114.

BOHEMAN C. H. 1861: Coleoptera samlade af J. A. Wahlberg I Syd-Vestra Afrika. Ofversigt af Kongliga Vetenskaps-Akademiens Forhandlingar 1860: 3-22.

BRANCH G. M. \& BRANCH M. L. 2018: Living Shores Interacting with Southern Africa's Marine Ecosystems. Second Edition. Penguin Random House, Cape Town, 336 pp.

BRANCH G. M., GRIFFITHS C. L., BRANCH M. L. \& BECKLEY L. E. 2017: Two Oceans: A Guide to the Marine Life of Southern Africa Third Edition. Penguin Random House, Cape Town, 464 pp.

GREENAN T. M., GRIFFITHS C. L. \& SANTAMARIA C. A. 2017: Phylogeography and cryptic diversity of intertidal Ligia isopods (Crustacea, Isopoda, Ligiidae) across the southern Africa coastline. PeerJ 6(e4658): 1-19.

HURTADO L. A., LEE E. J., MATEOS M. \& TAITI S. 2014: Global diversification at the harsh sea-land interface: mitochondrial phylogeny of the supralittoral isopod genus Tylos (Tylidae, Oniscidea). PLOS ONE 9(4) (e94081): 1-10.

JÄCH M. A. \& DELGADO J. A. 2014: Revision of the Palearctic species of the genus Ochthebius Leach XXIX. The Asian species of the O. vandykei group (Coleoptera: Hydraenidae). Koleopterologische Rundschau 84: 81-100.

KENSLEY B. 1972: Behavioural adaptations of the isopod Tylos granulatus Krauss. Zoologica Africana 7: 1-4.

MBONGWA N. A. 2018: A hidden world beneath the sand: Testing phylogeographic and biogeographic patterns of southern African sandy beach species. MSc Thesis, Department of Zoology, University of Stellenbosch, South Africa, xiv +110 pp.

MBONGWA N. A., HUI C., PULFRICH A. \& VON DER HEYDEN S. 2019: Every beach an island - deep population divergence and possible loss of genetic diversity in Tylos granulatus, a sandy shore isopod. Marine Ecology Progress Series 614: 111-123.

ORCHYMONT A. D'. 1933: Au sujet de trois Ochthebius africains. Bulletin et Annales de la Société Entomologique de Belgique 73: 406-414.

PÉRINGUEY L. A. 1892: Fourth contribution to the South African coleopterous fauna. Transactions of the South African Philosophical Society 6(2): 95-134.

PERKINS P. D. 1997: Life on the effective bubble: exocrine secretion delivery systems (ESDS) and the evolution and classification of beetles in the family Hydraenidae (Insects: Coleoptera). Annals of the Carnegie Museum 66: 89-207.

PERKINS P. D. \& BALFOUR-BROWNE J. 1994: A contribution to the taxonomy of aquatic and humicolous beetles of the family Hydraenidae in southern Africa. Fieldiana Zoology 77: 1-159.

RIBERA I. \& FOSTER G. N. 2018: Report of Frank Balfour-Browne's collecting in Gran Canaria and Madeira (1932-1933), with the description of Ochthebius (Cobalius) lanthanus sp. nov. (Coleoptera, Hydraenidae). Zootaxa 4524: 65-76.

RIEDELA. 2005: Digital imaging of beetles (Coleoptera), and other threedimensional insects. Pp. 222-250. In: HÄUSER C., STEINER A., HOLSTEIN J. \& SCOBLE M. J. (eds): Digital Imaging of Biological Type Specimens. A Manual of Best Practice. Results from a study of the European Network for Biodiversity Information, Stuttgart, 309 pp.

SABATELLI S., AUDISIO P., ANTONINI G., SOLANO E., MARTINOLI A. \& TRIZZINO M. 2016: Molecular ecology and phylogenetics of the water beetle genus Ochthebius revealed multiple independent shifts to marine rockpools lifestyle. Zoologica Scripta 45: 175-186.

SANTAMARIA C. A., BLUEMEL J. K., BUNBURY N. \& CURRAN M. 2017: Cryptic biodiversity and phylogeographic patterns of Seychellois Ligia isopods. PeerJ 5(e3894): 1-18.

SANTAMARIA C. A., MATEOS M., DEWITT T. J. \& HURTADO L. A. 2016: Constrained body shape among highly genetically divergent allopatric lineages of the supralittoral isopod Ligia occidentalis (Oniscidea). Ecology and Evolution 6: 1537-1554.

URBANELLI S. 2002: Genetic divergence and reproductive isolation in the Ochthebius (Calobius) complex (Coleoptera: Hydraenidae). Heredity 88: 333-341.

URBANELLI S. \& PORRETTA D. 2008: Evidence of reinforcement of premating isolation between two species of the genus Ochthebius (Coleoptera: Hydraenidae). Evolution 62: 1520-1527.

URBANELLI S., SALLICANDRO P., DE VITO E., COLONNELLI E. \& BULLINI L. 1996: Molecular reexamination of the taxonomy of Ochthebius (Calobius) (Coleoptera: Hydraenidae) from the Mediterranean and Macaronesian Regions. Annals of the Entomological Society of America 89: 623-636.

VILLASTRIGO A., HERNANDO C., MILLÁN A. \& RIBERA I. 2020: The neglected diversity of the Ochthebius fauna from Eastern Atlantic and Central and Western Mediterranean coastal rockpools (Coleoptera, Hydraenidae). Organisms Diversity and Evolution 20: 785-801.

VILLASTRIGO A., JÄCH M. A., CARDOSO A., VALLADARES L. F. \& RIBERA I. 2019: A molecular phylogeny of the tribe Ochthebiini (Coleoptera, Hydraenidae, Ochthebiinae). Systematic Entomology 44: $273-288$

VON DER HEYDEN S. 2009: Why do we need to integrate population genetics into South African marine protected area planning? African Journal of Marine Science 31: 263-269. 